\title{
Morphological Study of the Craniofacial Skeleton of the Unilateral Cleft Lip and Palate with Anterior Crossbite
}

\author{
MUTSUO YAKEISHI \\ Department of Oral Surgery, Kurume University School of Medicine, Kurume, 830 Japan
}

Received for publication November 2, 1987

\begin{abstract}
Summary: Sixty cleft lip and palate crossbite patients from the Kurume University School of Medicine Hospital were compared with 60 non-cleft, crossbite subjects. Their facial morphologic differences were analyzed by comparing their lateral cephalograms prior to orthodontic therapy. The following results were obtained: 1 . In the anterior region of the facial profile of the cleft sample, marked suppression of growth in the forward of the upper and lower jaws was observed. 2. The antero-posterior diameter of the cranial base in the cleft sample was small in the cleft compared to the control sample. Cranial base angle was somewhat flattened in the cleft sample; this effect was not significant. 3. The antero-posterior diameter of the maxilla was significantly smaller in the cleft sample; furthermore maxilla showed the lack of growth and was positioned in the upward/posterior location. 4. The following positional and morphologic changes of the mandible were observed in the cleft sample: retrusion of point $\mathrm{B}$, shortening of the mandibular ramus height, and enlargement of the mandibular plane angle. 5. Thickness of the mandibular symphysis at Point B was significantly narrower while the symphysis height was significantly greater in the cleft sample. Marked lingual inclination of the symphysis was observed in the cleft sample. 6. As there was a lack of growth of the maxilla in the cleft sample, the skeletal profile of the maxillo-mandibular relationship became concave in this sample, and this condition was progressively worsening with age. All these findings suggest that for appropriate orthodontic treatment of the cleft lip and palate patient, it is necessary to guide and promote the growth of the maxilla to the forward/downward direction with the early use of orthopedic force. Furthermore, because of the distortion of the symphysis contour and its further alterations with age in the cleft sample, it will be difficult to incline the lower teeth lingually; this makes the treatment of cleft lip and palate patients much more difficult.
\end{abstract}

Key words: cleft lip and palate - anterior crossbite - cephalometric study morphological changes - oral and maxillofacial surgery

\section{Introduction}

Understanding the development pattern of the craniofacial complex unique to children with cleft lip and palate is a prerequisite in orthodontic diagnosis and therapy. The children with the stated congenital anomaly, who underwent reconstructive surgery at infancy where active growth develpoment takes place, often suffer resultant malformations in the form of malocclusion and mal-alignment of dentition. Concomitant stomatologic dysfunctions such as masticatory and phonetic disorders occur, often leading to subsequent psychological problems as well. 
For these cleft and palate patients, the comprehensive therapy involving the orthodontics, posthodontics, oral surgery, reconstructive surgery, speech therapy, otorhinology and pediatrics is required from the infancy till adulthood.

In particular, post-operative mal-occlusion due to positional mal-relationship the upper and lower jaws and/or mal-position of teeth give rise to functional difficulties in mastication, deglutition, and phonetics. Thus, orthodontic management is essential in resolving the aformentioned dysfunctions.

From this perspective, orthodontist who renders treatment to the said patients ought to possess fundamental knowledge of their craniofacial complex development pattern, which is central to the diagnosis, treatment plan and prognosis of orthodontic therapy.

Graber was the first to use profilograms in 1949 to report structural analysis of the craniofacial complex of a patient with cleft lip and palate. Since then, numerous morphologic and growth and developmental studies pertaining to the stated topic have been carried out (Ishikawa et al. 1970a, $b$; Sekiguchi, 1971; Shibasaki, 1973; Hama, 1964; Harvolt, 1954; Mazaheri et al. 1967; Nakamura et al. 1972). However, most of these reports dealt with subjects with a limited age bracket who presented different types of cleft lip and palate only. At the same time, the controls used were mainly normal occlusion samples taken from the general population.

In this investigation, growth patterns of the craniofacial complex of the 4 to 12 years old unilateral cleft lip and palate patients were analyzed by using the lateral cephalograms.

Crossbite subjects were used as the controls since most of the cleft lip and palate patients have the anterior crossbite concomitant with underdeveloped maxilla.

Furthermore, the mandibular symphy- ses, which affect strongly the orthodontic management of crossbite patients, were investigated. Specifically the morphologic and structural changes which occur with increasing age were analyzed. The purpose of this study was to compare and analyze morphologic differences between two groups of patients. In addition, attempt was made to find out how orthodontic treatment differs among children with similar crossbites.

\section{Materials and Methods}

Subjects: The study population consisted of 60 lateral cephalograms randomly selected from the patient pool of the Kurume University School of Medicine Hospital. All of the subjects exhibited similar, repaired complete unilateral cleft lip and palate with concomitant anterior crossbite. All of them have had common past history of undergoing reconstruction cleft surgery at infancy with no subseqent orthodontic or surgical management such as pharyngeal flap operation. The age range was from 4 to 12 years. Certain subjects underwent the Tennison cheiloplasty procedures at the age of 3 months.

Others were the subjects of the modified palatal pushback procedure at 1 year 6 months of age postbirth. The subjects were divided into three groups twenty subjects each, based on their age bracket: group A, 4 years 2 months to 6 years; group B, 7 years 4 months to 9 years 11 months; group C, 10 years 3 months to 12 years 9 months of age.

For the control sample, 60 anterior crossbite patients of similar age with no concomitant cleft anomalies were selected at random from the patient files at the Fukuoka Dental College Hospital (Table 1); they were devided into three groups (A-C), similar to those of the cleft lip and palate subjects. 
TABLE 1

Sample size, mean age and range

\begin{tabular}{|c|c|c|c|c|c|}
\hline & & & $\underset{\text { Group }}{\text { A }}$ & $\underset{\text { Group }}{\mathrm{B}}$ & $\underset{\text { Group }}{\mathrm{C}}$ \\
\hline \multirow{4}{*}{$\begin{array}{l}\text { Cleft } \\
\quad \text { sample }\end{array}$} & \multirow{4}{*}{ Age } & $\mathrm{N}$ & 20 & 20 & 20 \\
\hline & & Mean & $5 \mathrm{Y} 1 \mathrm{M}$ & $8 \mathrm{Y} 7 \mathrm{M}$ & $11 \mathrm{Y} 6 \mathrm{M}$ \\
\hline & & Min & $4 \mathrm{Y} 2 \mathrm{M}$ & $7 \mathrm{Y} 4 \mathrm{M}$ & $10 \mathrm{Y} 3 \mathrm{M}$ \\
\hline & & $\operatorname{Max}$ & $6 \mathrm{Y} 0 \mathrm{M}$ & $9 \mathrm{Y} 11 \mathrm{M}$ & $12 \mathrm{Y} 9 \mathrm{M}$ \\
\hline \multirow{4}{*}{$\begin{array}{l}\text { Control } \\
\text { sample }\end{array}$} & \multirow{4}{*}{ Age } & $\mathrm{N}$ & 20 & 20 & 20 \\
\hline & & Mean & $5 \mathrm{Y} 1 \mathrm{M}$ & $8 \mathrm{Y} 6 \mathrm{M}$ & $11 \mathrm{Y} 5 \mathrm{M}$ \\
\hline & & Min & $4 \mathrm{Y} 2 \mathrm{M}$ & $7 \mathrm{Y} 6 \mathrm{M}$ & $10 \mathrm{Y} 6 \mathrm{M}$ \\
\hline & & $\operatorname{Max}$ & $5 \mathrm{Y} 11 \mathrm{M}$ & $9 \mathrm{Y} 7 \mathrm{M}$ & $12 \mathrm{Y} 4 \mathrm{M}$ \\
\hline
\end{tabular}

N : Sample size

\section{Landmarks and Measurements}

Lateral cephalograms of the patients in centric occlusion were used. In the analysis of the protocol for the headplates the standard technique for lateral exposures (focusobject distance of 1.50 meters; focus-film distance of 1.65 meters) was employed. Using the 0.003 matte acetate tracing papers, facial skeletal and dental outlines were constructed. Certain landmarks with duplicates, e.g., orbital rims, were averaged out, and the midpoints were selected as the representative references. Three separate tracings per headplates were recorded and differences were averaged out for all cases. The following anthropometric landmarks and reference points, planes and angles were defined according to Downs (1948), Iizuka and Ishikawa (1957a, b), Sakamoto (1959) and Matsuda (1982).

\section{Craniofacial Complex Measurements}

1. Landmarks, reference points and lines.

The landmarks are illustrated in Fig. 1; they may be defined as follows:

S (Sella turcica): The center of the bony crypt of the hypophysis cerebri.

$\mathrm{N}$ (Nasion): The most anterior point of frontnasal suture in the median plane.

Or (Orbitale): The most inferior point

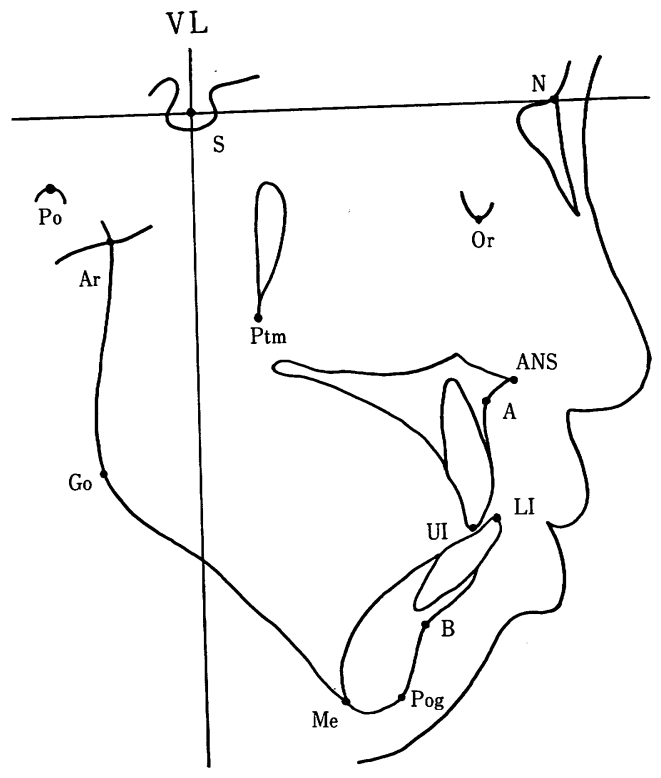

Fig. 1. Measurement points and the $\mathrm{X}-\mathrm{Y}$ co-ordinates.

on the external border of the orbital cavity, tangent to Frankfort Horizontal plane.

ANS (Anterior nasal spine): The spinous process of the maxilla forming the most anterior projection of the nasal cavity floor.

PNS (Posterior nasal spine): The spinous process formed by the most posterior projection of the juncture of palatine bones in the midline of the oral cavity floor.

Point A (Subspinale): The deepest midline point on the premaxilla between the anterior nasal spine and the crest of the maxillary alveolar process.

Point B (Supramentale): The most posterior point in the concavity between infradentale and pogonion.

Pog (Pogonion): The most anterior point on symphysis of mandible.

Me (Menton): The most caudal point on the outline of symphysis.

Go (Gonion): The point at which the jaw angle is most inferiorly, posteriorly and outwardly directed. 
Ar (Articulare): The intersection of basisphenoid and posterior border of condyle.

Ptm (Pterygomaxillary fissure): The intersection of inferior border of foramen rotundum with the posterior wall of pterygomaxillary fossa.

Po (Porion): The midpoint on upper edge of porus acusticus externus.

Ptm': Intersection of line perpendicular to Frankfort Horizontal plane with Ptm.

$\mathrm{A}^{\prime}$ : Intersection of line perpendicular to $\mathrm{FH}$ plane with point $\mathrm{A}$.

UI (Upper incisor): Incisal point of the most prominent medial maxillary incisor.

LI (Lower incisor): Incisal point of the most prominent medial mandibular incisor.

Id (Infradentale): Alveolar rim of mandible, the highest most anterior point on alveolar process in median plane between the mandibular central incisors.

Id' (Lingual infradentale): Alveolar rim of mandible, the highest most posterior point on alveolar process in median plane between mandibular central incisors.

Idm: The midpoint between Id and Id'.

SN plane: The cranial line through $\mathrm{N}$ and $S$ (see above) representing the anterior cranial base plane.

NF plane (Nasal floor): Palatal "plane" through ANS and PNS (see above).

FH plane (Frankfort Horizontal plane): Line linking Or and Po (see above).

MP (Mandibular plane): Line tangent to the lower border of mandible through $\mathrm{Me}$.

VL plane (Vertical plane): Line perpendicular to SN plane through S.

\section{Measurements of the craniofacial height and depth.}

The pertinent landmarks are shown in Fig. 1. Nine variables which are pertinent for these measurements are shown in Table 4 ; ten pertinent variables are shown in Table 5. The reference lines for the $\mathrm{X}$-axis and the $\mathrm{Y}$-axis were $\mathrm{SN}$ and $\mathrm{VL}$, respectively.
Linear horizontal measurements were carried out from the VL plane to each landmark parallel to the SN plane. Vertical measurements were carried out from the SN line to each landmark parallel to the VL. Measurements were recorded in millimeters from the respective axes.

\section{Linear measurements of the craniofacial complex.}

The tracings and the construction of the planes are illlustrated in Fig. 2; the planes are defined as follows:

S-N: Anteroposterior extent of the anterior cranial base.

A'-Ptm': Length of maxilla (the distance between points $\mathrm{A}$ and $\mathrm{Ptm}$ as projected to the $\mathrm{FH}$ plane).

Ar-Go: Length of ramus (Posterior facial height).

Go-Me: Extent of mandibular body.

Ar-Me: Length of mandible.

$\mathrm{N}-\mathrm{Me}$ : Anterior facial height.

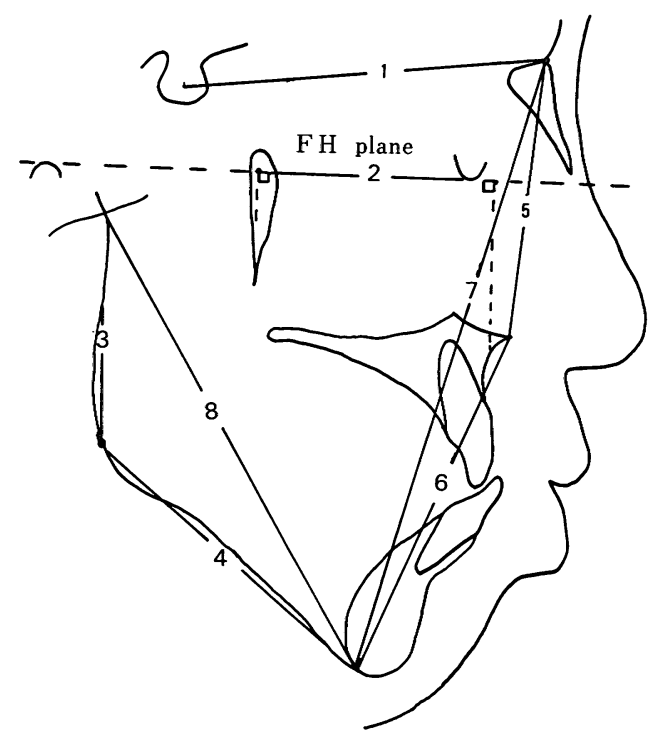

$$
\begin{array}{llll}
\text { 1: S-N } & 2: \text { A'-Ptm' }^{\prime} & 3: \text { Ar-Go } \\
4: \text { Go-Me } & 5: \text { N-ANS } & 6: \text { ANS-Me } \\
7: \text { N-Me } & 8: \text { Ar-Me } & &
\end{array}
$$

Fig. 2. Linear measurement variables. 
N-ANS: Upper facial height.

ANS-ME: Lower facial height.

\section{Angular measurements of the craniofacial complex.}

The pertinent tracings and constructions are shown in Fig. 3; the paramenters can be defined as follows:

NSAr: Saddle angle.

SNA: Anteroposterior position of maxilla.

SNB: Anteroposterior position of mandible.

ANB: Difference between SNA and SNB.

SN-MP: Angle between SN and mandibular plane.

Ramus angle: Angle between ramus plane and the line which was projected to the FH plane throuth point Ar.

Gonial angle: Angle between mandibular plane and ramus plane.

UI-SN : Angulation of upper central incisors.

LI-MP : Angulation of lower central incisors.

II. Dimensions of the mandibular symphysis.

Fig. 4 illustrates the traced structures, landmarks and lines. The dimensions may be defined as follows:

Symphysis height: The distance between Id and Id'.

Symphysis thickness at Point B: The intra-symphysis distance; the line is drawn from Point B, perpendicular to the line drawn through Idm and Me.

Symphysis thickness at Pogonion: The intra-symphysis distance is drawn from Pogonion perpendicular to the line drawn through Idm and Me.

Lingual inclination of symphysis: The angle formed between mandibular plane and the line drawn through Idm and Me.
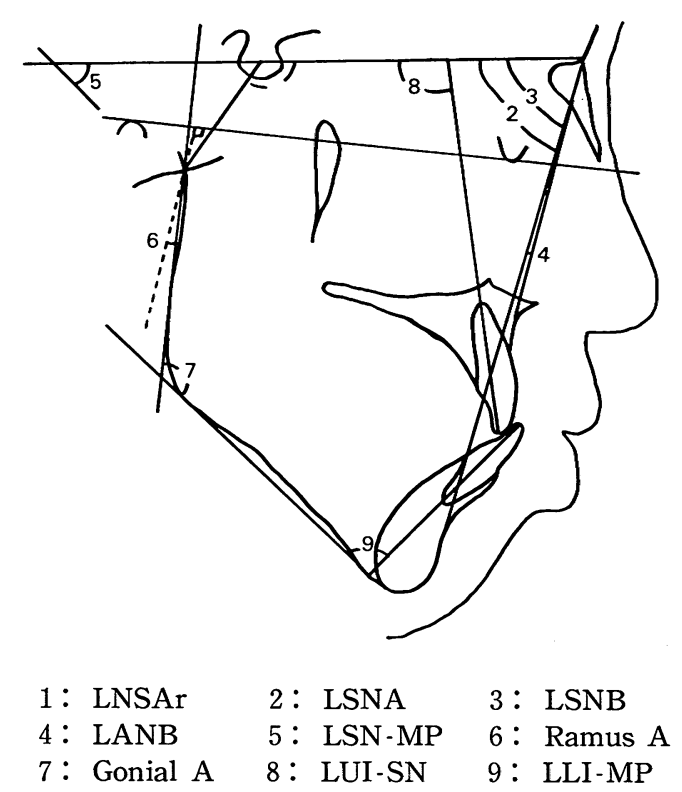

Fig. 3. Angular measurement variables.

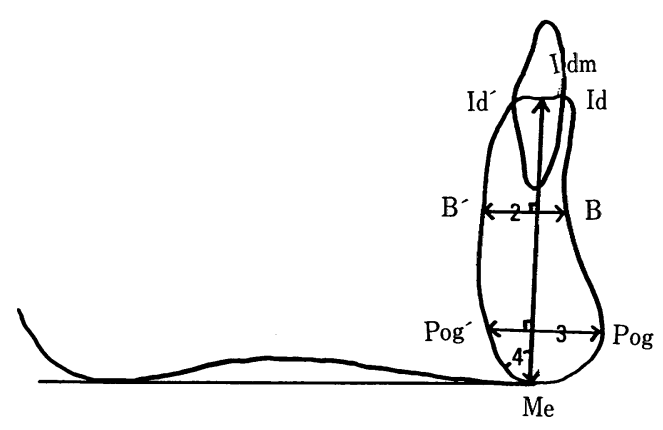

1: Idm-Me 2: B-Perpendicular $\mathrm{Me} \cdot \mathrm{Idm}$

3: Pog-Perpendicular $\mathrm{Me} \cdot \mathrm{Idm}$

4: <MPto $\mathrm{Me} \cdot \mathrm{Idm}$

Fig. 4. Point and linear measurement variables of mandibular symphysis. 


\section{Statistical Analysis}

The following statistical criteria were computed for each lateral cephalogram: mean averages, standard deviations, and confidence intervals of the means at each age level of the unilateral cleft and noncleft subjects. The growth changes of each variable of the craniofacial complex were analyzed statistically.

From the mean values of each variable, profile diagrams were constructed and superimposed for each age level in both cleft and control samples. The craniofacial complex growth patterns were then compared between the cleft and the control samples. Moreover, the structural differences between the two samples of the mandibular symphysis were examined at their age levels.

\section{Results}

\section{Linear Measurements}

Table 2 shows the means and standard deviations of the measurements for the control and cleft samples; statistical levels of sigificance for the differences are shown as well.

TABLE 2

Linear measurements in cleft and control samples

\begin{tabular}{|c|c|c|c|c|c|c|c|c|c|c|c|}
\hline \multirow{2}{*}{ Varlable } & \multirow{2}{*}{\multicolumn{2}{|c|}{ Sample }} & \multicolumn{3}{|c|}{ Age Group } & \multirow{2}{*}{ Variable } & \multirow{2}{*}{\multicolumn{2}{|c|}{ Sample }} & \multicolumn{3}{|c|}{ Age Group } \\
\hline & & & \multirow{3}{*}{\multicolumn{2}{|c|}{$\begin{array}{cc}\text { A } & \text { B } \\
62.07 & 064.25 \\
2.67 & 2.35\end{array}$}} & \multirow{3}{*}{$\begin{array}{r}\mathrm{C} \\
66.04 \\
2.86\end{array}$} & & & & \multirow{2}{*}{$\frac{\mathrm{A}}{83.97}$} & B & \multirow{2}{*}{$\frac{C}{99.33}$} \\
\hline \multirow{5}{*}{$\mathrm{S}-\mathrm{N}$} & Cleft & Mean & & & & \multirow{5}{*}{$\mathrm{Ar}-\mathrm{Me}$} & \multirow[t]{3}{*}{ Cleft } & Mean & & $94.21 \bullet$ & \\
\hline & & S.D & & & & & & S.D & 4.98 & 7.32 & 5.13 \\
\hline & \multirow{3}{*}{ Control } & \multirow{3}{*}{$\begin{array}{l}\text { Mean } \\
\text { S.D }\end{array}$} & \multirow{3}{*}{\multicolumn{2}{|c|}{$\begin{array}{rrr}62.62 & \circ & 65.68 \\
2.77 & & 3.63 \\
\end{array}$}} & \multirow{3}{*}{$\begin{array}{r}66.79 \\
3.12 \\
\end{array}$} & & & \multirow{3}{*}{$\begin{array}{l}\text { Mean } \\
\text { S.D }\end{array}$} & $*$ & $*$ & $*$ \\
\hline & & & & & & & \multirow[t]{2}{*}{ Control } & & $93.33 \bullet$ & $96.63 \circ$ & 104.63 \\
\hline & & & & & & & & & 2.70 & 5.11 & 7.53 \\
\hline \multirow{5}{*}{$\mathrm{A}^{\prime}-\mathrm{Ptm}$} & Cleft & Mean & 41.54 & 42.02 & 42.15 & \multirow{5}{*}{$\mathrm{N}-\mathrm{ANS}$} & \multirow[t]{3}{*}{ Cleft } & \multirow{3}{*}{$\begin{array}{l}\text { Mean } \\
\text { S. D }\end{array}$} & $43.78 \bullet$ & $46.38 \bullet$ & 48.56 \\
\hline & & S.D & 3.54 & 1.70 & 3.23 & & & & 3.14 & 4.30 & 3.52 \\
\hline & \multirow{3}{*}{ Control } & & $*$ & $*$ & $*$ & & & & $*$ & $*$ & $*$ \\
\hline & & Mean & 43.13 & 44.25 & 45.35 & & \multirow[t]{2}{*}{ Control } & Mean & $46.20^{\circ}$ & $49.38 \bullet$ & 53.68 \\
\hline & & S. D & 2.13 & 2.18 & 2.73 & & & S. D & 2.30 & 2.85 & 3.46 \\
\hline \multirow{5}{*}{ Ar-Go } & Cleft & Mean & \multicolumn{3}{|c|}{$36.25 \circ 38.30 \circ 40.88$} & \multirow{5}{*}{ ANS-Me } & \multirow[t]{3}{*}{ Cleft } & Mean & $59.66 \bullet$ & 65.33 & 65.60 \\
\hline & & S.D & 2.76 & 3.75 & 3.48 & & & S. D & 4.03 & 4.08 & 3.96 \\
\hline & \multirow{3}{*}{ Control } & & * & $*$ & $*$ & & & & & & \\
\hline & & Mean & 37.75 & 40.27 & 43.55 & & \multirow[t]{2}{*}{ Control } & Mean & $58.33^{\circ}$ & $63.20 \ominus$ & 64.18 \\
\hline & & S. D & 3.29 & 3.02 & 3.88 & & & S.D & 3.43 & 3.23 & 5.34 \\
\hline & Cleft & Mean & 60.76 & 65.28 & 67.86 & & Cleft & Mean & 101.31 & 113.47 & 114.98 \\
\hline & & S.D & 4.77 & 4.71 & 3.48 & & & S.D & 3.73 & 7.53 & 4.74 \\
\hline Go-Me & & & $*$ & $*$ & $*$ & $\mathrm{~N}-\mathrm{Me}$ & & & & & \\
\hline & Control & Mean & 62.45 & 67.76 & 71.48 & & Control & Mean & 103.13 & $111.05 \bullet$ & 117.18 \\
\hline & & S.D & 2.38 & 3.38 & 5.49 & & & S.D & 3.98 & 4.83 & 7.38 \\
\hline
\end{tabular}

See text for abbrevited landmarks, reference points and lines. Numerals: distances in $\mathrm{mm}$. Age group: A, 4 years 2 months to 6 years; B, 7 years 4 months to 9 years 11 month; C, 10 years 3 months to 12 years 9 months. Asterisks $\left(^{*}\right)$ indicate statistically significant dif ferences between cleft and control samples. Solid circles $(\bullet)$ indicate statistically significant differences between age groups. 
The S-N variable, which measures the antero-posterior growth of the cranial base, showed no significant differences for all three age Groups A, B, C for the cleft and control samples. Also the rates of change relative to age were similar in both samples.

The A'-Ptm' variable which measures the antero-posterior growth of the maxilla was significantly smaller in cleft samples as compared to controls. The control sample displayed an increase of this variable concomitant with increase in age. On the other hand, the increase was not significantly among the Groups in the cleft sample.

As for the growth of the mandible, the difference between the cleft and control samples in the Ar-Go dimension was statistically significant, as the cleft sample exhibited a lesser change with age for Groups A-C than the control sample.

Similarly, Go-Me and $\mathrm{Ar}-\mathrm{Me}$ variables showed small changes with age among the respective cleft Groups, in comparison to the control samples, although both samples displayed an increase in these variables concomitant with age.

$\mathrm{N}-\mathrm{Me}, \mathrm{N}-\mathrm{ANS}$ and ANS-Me veriables describe the facial height. The total facial height $(\mathrm{N}-\mathrm{Me})$ showed no significant difference between the cleft and control samples. Both samples displayed a significant increase concomitant with age, except for Groups B and C in the cleft samples.

In the case of the upper facial height (N-ANS), this dimension increased significantly less with age in the cleft sample relative to the controls. The changes were statistically significant relative to age in both samples.

On the other hand, in the case of the lower faical height (ANS-Me), no statistically siginificant differences were observed between the cleft and control samples in all age groups, although the ANS$\mathrm{Me}$ values were generally higher for the cleft samples.

\section{Angle Measnrements}

The NSAr angle which is formed between the anterior cranial base and the posterior cranial base, showed large variability in the cleft sample as compared with the control; the differences between the two samples for 3 age groups were not significant. Nor was the rate of change with age significantly different between the two samples.

The SNA angle which represents the antero-posterior position of the maxilla, was significantly smaller in all 3 Groups A, B and C of the cleft sample as compared to the controls. There was no change with respect to age in either samples.

The SNB angle, which represents the antero-posterior position of the mandible, was significantly smaller in the cleft samples compared to controls; this was true for all age Groups. Both cleft and control samples showed increase with age; however significant change occurred only between the $\mathrm{B}$ and $\mathrm{C}$ groups in the control sample.

The SN-MP variable which represents the angle formed between the cranial base and the mandibular plane was significantly larger in the cleft sample, compared to controls; this was true for every age group.

There were no significant differences among the age groups in the two samples, except between groups $\mathrm{A}$ and $\mathrm{B}$ in the control sample.

The gonial angle (Gonial A) was larger in the cleft sample, but the difference was not significant. Nor was there any significant change with age among the groups A-C within each sample. The ramus angle (ramus A) which represents the angle between the $\mathrm{FH}$ and ramus planes was smaller in the cleft relative to the control sample, but the difference was not significant.

The ANB angle which represents the maxillo-mandibular relationship was significantly smaller in the cleft sample relative to controls; this was true for all age groups.

Interestingly, cleft samples showed de- 
TABLE 3

Angular measurements in cleft and control samples

\begin{tabular}{|c|c|c|c|c|c|}
\hline \multirow{2}{*}{ Variable } & \multirow{2}{*}{\multicolumn{2}{|c|}{ Sample }} & \multicolumn{3}{|c|}{ Age Group } \\
\hline & & & A & B & C \\
\hline \multirow{4}{*}{ NSAr } & Cleft & Mean & 126.13 & 127.27 & 126.01 \\
\hline & & S.D & 5.54 & 6.56 & 3.93 \\
\hline & Control & Mean & 123.25 & 124.10 & 125.75 \\
\hline & & S.D & 4.84 & 4.53 & 4.86 \\
\hline \multirow{5}{*}{ S NA } & Cleft & Mean & 75.83 & 75.42 & 74.30 \\
\hline & & S.D & 4.44 & 3.15 & 3.61 \\
\hline & & & $*$ & $*$ & $*$ \\
\hline & Control & Mean & 80.85 & 79.96 & 79.59 \\
\hline & & S.D & 3.54 & 2.75 & 3.80 \\
\hline \multirow{5}{*}{ S N B } & Cleft & Mean & 75.02 & 76.31 & 77.12 \\
\hline & & S.D & 3.94 & 3.16 & 3.10 \\
\hline & & & $*$ & $*$ & $*$ \\
\hline & Control & Mean & 77.51 & 78.68 & • 81.22 \\
\hline & & S.D & 3.07 & 2.54 & 3.62 \\
\hline \multirow{5}{*}{ SN-MP } & Cleft & Mean & 39.68 & 38.84 & 39.02 \\
\hline & & S.D & 6.58 & 4.78 & 4.77 \\
\hline & & & * & $*$ & $*$ \\
\hline & Control & Mean & 33.22 & - 35.31 & 35.02 \\
\hline & & S.D & 3.78 & 3.77 & 4.53 \\
\hline \multirow{4}{*}{ Ramus A } & Cleft & Mean & 8.30 & 8.76 & 8.54 \\
\hline & & S.D & 3.13 & 4.95 & 4.76 \\
\hline & Control & Mean & 9.28 & 9.47 & 10.71 \\
\hline & & S.D & 3.39 & 4.30 & 3.71 \\
\hline
\end{tabular}

\begin{tabular}{|c|c|c|c|c|c|}
\hline \multirow{2}{*}{ Variable } & \multirow{2}{*}{\multicolumn{2}{|c|}{ Sample }} & \multicolumn{3}{|c|}{ Age Group } \\
\hline & & & A & B & $\mathrm{C}$ \\
\hline \multirow{4}{*}{ Gonial A } & Cleft & Mean & 128.23 & 130.21 & 129.95 \\
\hline & & S.D & 5.21 & 4.69 & 5.94 \\
\hline & Control & Mean & 126.76 & 128.44 & 128.06 \\
\hline & & S.D & 5.14 & 5.36 & 4.81 \\
\hline \multirow{5}{*}{$\mathrm{ANB}$} & Cleft & Mean & 0.81 & -0.89 & -2.22 \\
\hline & & S.D & 1.51 & 0.81 & 2.25 \\
\hline & & & & * & * \\
\hline & Control & Mean & 4.34 & 1.28 & -1.63 \\
\hline & & S.D & 2.01 & 1.89 & 3.20 \\
\hline \multirow{5}{*}{ UI-SN } & Cleft & Mean & 75.48 & 93.34 & 92.17 \\
\hline & & S.D & 13.35 & 6.19 & 11.22 \\
\hline & & & $*$ & $*$ & $*$ \\
\hline & Control & Mean & 94.96 & 100.45 & 102.20 \\
\hline & & S. D & 9.38 & 6.91 & 7.76 \\
\hline \multirow{5}{*}{ LI-MP } & Cleft & Mean & 85.80 & 83.86 & 83.13 \\
\hline & & S.D & 6.88 & 5.19 & 7.17 \\
\hline & & & * & * & * \\
\hline & Control & Mean & 87.79 & 88.61 & 88.88 \\
\hline & & S.D & 7.31 & 5.31 & 5.73 \\
\hline
\end{tabular}

Numerals: angular measures $\left({ }^{\circ}\right)$. See Table 2 for abbreviations and symbols.

creasing values between groups $\mathrm{B}$ and $\mathrm{C}$, while significant decrease was observed in control sample with age.

Relative to the control, UI-SN and LIMP angles of the cleft sample were significantly smaller in the case of all groups than the controls. Mean values increased in the control sample with age, indicating age-related tendency with respect to labial inclination. In the cleft sample the angles decreased significantly from Group B to C, indicating a lingual inclination tendency in the UI to SN variable. Concurrently, LIMP decreased significanty in value in the cleft sample. Within the groups of the control sample, the mean values increased significantly with age; in other words, labial inclination age-related tendency was noted. However, within the groups of the cleft sample, the value decreased with age, indicating that there is an age-related lingual inclination tendeny.

\section{Height and Depth Measurements}

Tables 4 and 5 compare for the two samples the mean values and standard deviations of the height and depth variables which represent the contour of the maxillofacial complex, while graphic representations (cephalograms) derived from these 
TABLE 4

Height measurements in cleft and control samples

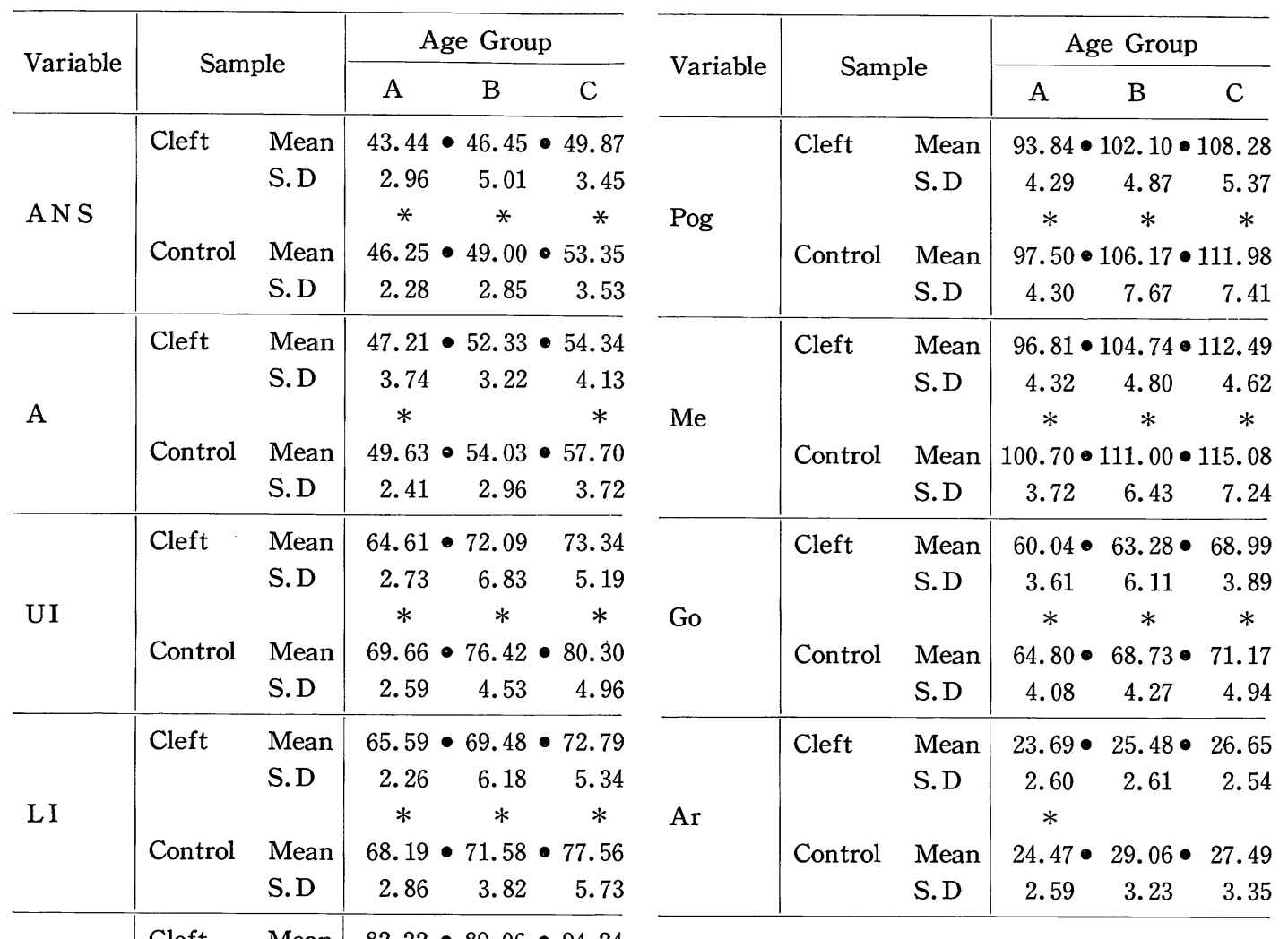

Numerals: distances in $\mathrm{mm}$. See Table 2 for abbreviations and symbols.

measurements are shown in Fig. 5 and 6.

In the figures the $\mathrm{S}-\mathrm{N}$ plane was lined to coincide with the $\mathrm{X}$-axis; sella turcica was defined as the origin (Point 0,0 ). By plotting the height and depth measurements of the variables, the profilograms were superimposed for each group and sample.

Fig. 5 $\mathrm{A}$ and $5 \mathrm{~B}$ correspond to the cleft and control samples, respectively, describing the contour changes within each sample, relative to increase in age within the contex of each Group. All mean height values of the cleft samples were significantly smaller, relative to the control samples.

The values for both control and cleft samples increased significantly with age. However, the amount of increase with age was small in the case of the cleft sample.

Mean values for depth were significantly smaller in all of the cleft samples compared to the controls, except for N. In the control sample there was an increase of individual measurements relative to increase in age. In the case of the cleft 
TABLE 5

Depth measurements in cleft and control samples

\begin{tabular}{|c|c|c|c|c|c|c|c|c|c|c|c|}
\hline \multirow{2}{*}{ Variable } & \multirow{2}{*}{\multicolumn{2}{|c|}{ Sample }} & \multicolumn{3}{|c|}{ Age Group } & \multirow{2}{*}{ Variable } & \multirow{2}{*}{\multicolumn{2}{|c|}{ Sample }} & \multicolumn{3}{|c|}{ Age Group } \\
\hline & & & \multirow{3}{*}{$\begin{array}{c}\mathrm{A} \\
62.07 \\
2.67\end{array}$} & \multirow{2}{*}{$\frac{B}{64.25}$} & \multirow{3}{*}{$\begin{array}{c}\mathrm{C} \\
66.04 \\
2.86\end{array}$} & & & & A & B & $\mathrm{C}$ \\
\hline \multirow{5}{*}{$\mathrm{N}$} & Cleft & Mean & & & & \multirow{5}{*}{ B } & Cleft & Mean & 41.38 & 42.98 & - 46.36 \\
\hline & & S.D & & 2.35 & & & & S.D & 5.42 & 6.14 & 3.48 \\
\hline & & & & & & & & & $*$ & $*$ & \\
\hline & Control & Mean & 62.62 & 65.68 & 66.79 & & Control & Mean & $45.80 \bullet$ & 49.01 & - 52.65 \\
\hline & & S.D & 2.77 & 3.63 & 3.12 & & & S. D & 4.03 & 5.15 & 7.15 \\
\hline \multirow{5}{*}{ A NS } & Cleft & Mean & 56.43 & 56.58 & 57.83 & \multirow{5}{*}{ Pog } & Cleft & Mean & 37.80 & 40.05 & 44.40 \\
\hline & & S.D & 3.62 & 3.71 & 3.39 & & & S.D & 6.44 & 7.00 & 4.15 \\
\hline & & & * & $*$ & $*$ & & & & * & $*$ & $*$ \\
\hline & Control & Mean & 59.10 & 60.12 & 62.87 & & Control & Mean & $40.51 \bullet$ & 43.33 & - 48.52 \\
\hline & & S.D & 3.05 & 2.91 & 3.98 & & & S.D & 4.64 & 5.94 & 8.26 \\
\hline \multirow{5}{*}{ A } & Cleft & Mean & 51.12 & 52.43 & 53.27 & \multirow{5}{*}{$\mathrm{Me}$} & Cleft & Mean & 29.90 & 31.25 & - 33.94 \\
\hline & & S.D & 3.64 & 3.95 & 2.99 & & & S.D & 6.25 & 7.60 & 4.97 \\
\hline & & & * & $*$ & $*$ & & & & $*$ & $*$ & \\
\hline & Control & Mean & 53.80 & 55.91 & 56.27 & & Control & Mean & $37.00 \bullet$ & 39.14 & - 41.44 \\
\hline & & S.D & 2.73 & 3.47 & 4.19 & & & S.D & 4.94 & 5.90 & 7.47 \\
\hline \multirow{5}{*}{ UI } & Cleft & Mean & \multicolumn{3}{|c|}{$44.58 \odot 47.02 \bullet 49.41$} & \multirow{5}{*}{ Go } & Cleft & Mean & \multicolumn{2}{|c|}{$-13.10 \bullet-16.08$} & -14.81 \\
\hline & & S.D & 4.30 & 5.44 & 4.43 & & & S.D & 3.20 & 5.28 & 3.40 \\
\hline & & & * & * & $*$ & & & & & & \\
\hline & Control & Mean & 52.15 & 53.56 & 55.90 & & Control & Mean & $-11.97 \bullet$ & -15.35 & -14.67 \\
\hline & & S.D & 3.33 & 4.10 & 6.24 & & & S.D & 3.65 & 4.15 & 3.27 \\
\hline \multirow{5}{*}{ L I } & Cleft & Mean & \multicolumn{3}{|c|}{$49.28 \bullet 52.85 \bullet 56.49$} & \multirow{5}{*}{ Ar } & \multirow[t]{3}{*}{ Cleft } & Mean & $-14.83 \bullet$ & -18.80 & -19.02 \\
\hline & & S.D & 4.29 & 5.51 & 3.99 & & & S. D & 2.86 & 4.07 & 1.87 \\
\hline & & & $*$ & $*$ & $*$ & & & & & & \\
\hline & \multirow[t]{2}{*}{ Control } & Mean & 56.15 & 58.25 & 61.55 & & \multirow[t]{2}{*}{ Control } & Mean & \multicolumn{2}{|c|}{$-16.69 \bullet-18.16$} & -18.21 \\
\hline & & S.D & 3.53 & 4.12 & 9.30 & & & S.D & 2.37 & 2.43 & 1.98 \\
\hline
\end{tabular}

Numerals: distances in mm. See Table 2 for abbreviations and symbols.

sample, LI, B, Pog and Me showed significant increase among Groups with age, but there was no significant age-related increase in the case of ANS, A and UI.

ANS, A and UI of cleft samples showed tendency to be situated in an upward/posterior position, while LI, B, Pog and $\mathrm{Me}$ to be situated in posterior position (Fig. $6-\mathrm{A}, \mathrm{B}, \mathrm{C})$ as compared to the controls.

\section{Morphologic Changes of the Mandibular Symphysis}

Table 6 describes age-related morhologic changes of the mandibular symphysis of the cleft and control samples.

Symphysis diameter at point B was significantly smaller in all the age groups of the cleft sample as compared to controls. Although slight decrease was noticed concomitant with age in the cleft and control samples, significant decreases were observed only between groups $\mathrm{B}$ and $\mathrm{C}$ in the cleft sample.

Roughly same values were obtained in both the cleft and control for Pog (Table 5). 
TABLE 6

Mandibular symphysis measurements in cleft and control samples

\begin{tabular}{|c|c|c|c|c|c|c|c|c|c|c|c|}
\hline \multirow{2}{*}{ Variable } & \multirow{2}{*}{\multicolumn{2}{|c|}{ Sample }} & \multicolumn{3}{|c|}{ Age Group } & \multirow{2}{*}{ Variable } & \multirow{2}{*}{\multicolumn{2}{|c|}{ Sample }} & \multicolumn{3}{|c|}{ Age Group } \\
\hline & & & $\mathrm{A}$ & $\mathrm{B}$ & $\mathrm{C}$ & & & & $\mathrm{A}$ & B & $\mathrm{C}$ \\
\hline \multirow{5}{*}{ 吾总 } & Cleft & Mean & 8.38 & 8.14 & - 6.94 & \multirow{5}{*}{ 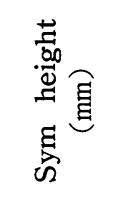 } & \multirow[t]{3}{*}{ Cleft } & \multirow{3}{*}{$\begin{array}{l}\text { Mean } \\
\text { S. D }\end{array}$} & 29.32 & 31.15 & 33.52 \\
\hline & & S.D & 1.27 & 1.28 & 3.51 & & & & 1.89 & 4.15 & 1.87 \\
\hline & & & $*$ & $*$ & * & & & & & $*$ & $*$ \\
\hline & \multirow[t]{2}{*}{ Control } & Mean & 9.60 & 9.01 & 8.55 & & \multirow[t]{2}{*}{ Control } & Mean & 28.05 & 27.90 & 29.65 \\
\hline & & S.D & 1.51 & 1.13 & 1.52 & & & S.D & 2.12 & 2.01 & 6.73 \\
\hline \multirow{5}{*}{ 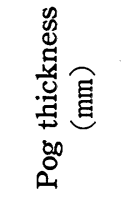 } & \multirow[t]{3}{*}{ Cleft } & Mean & 12.85 & 12.57 & 12.81 & \multirow{5}{*}{ 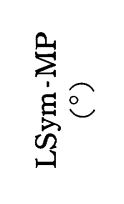 } & \multirow[t]{3}{*}{ Cleft } & Mean & 82.04 & 75.75 & 75.66 \\
\hline & & S. D & 1.60 & 1.18 & 2.35 & & & S. D & 4.96 & 4.93 & 4.62 \\
\hline & & & & & & & & & * & $*$ & * \\
\hline & \multirow[t]{2}{*}{ Control } & Mean & 13.72 & 12.91 & 12.97 & & \multirow[t]{2}{*}{ Control } & Mean & 82.25 & 80.70 & 79.74 \\
\hline & & S.D & 1.40 & 1.23 & 1.66 & & & S. D & 3.94 & 4.27 & 5.02 \\
\hline
\end{tabular}

See Table 2 for abbreviations and symbols.

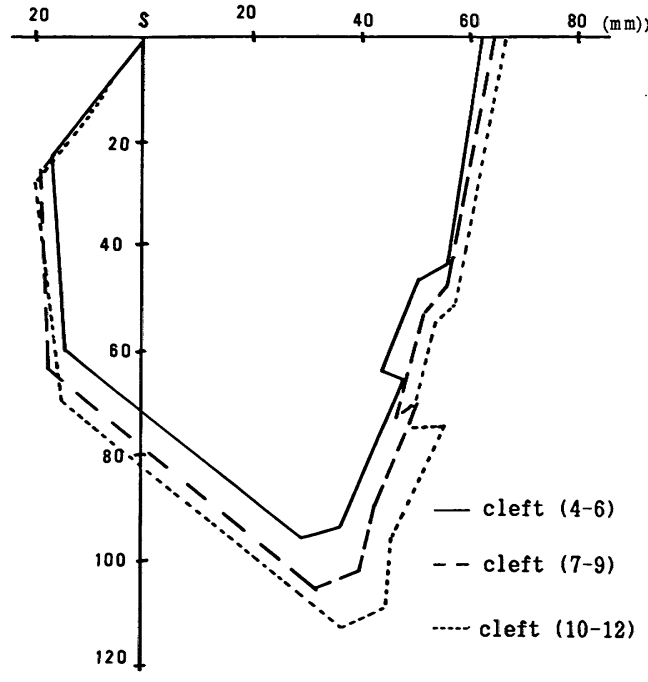

A

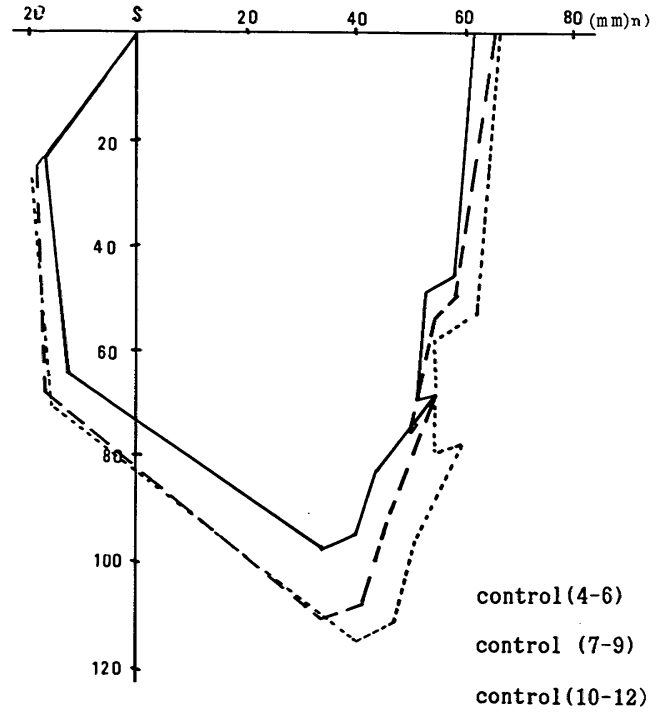

B

Fig. 5. Superimposed cephalograms of various age Groups A, B, and C by cleft and control samples.

$A$ represents celft sample; $B$ represents control samples. 


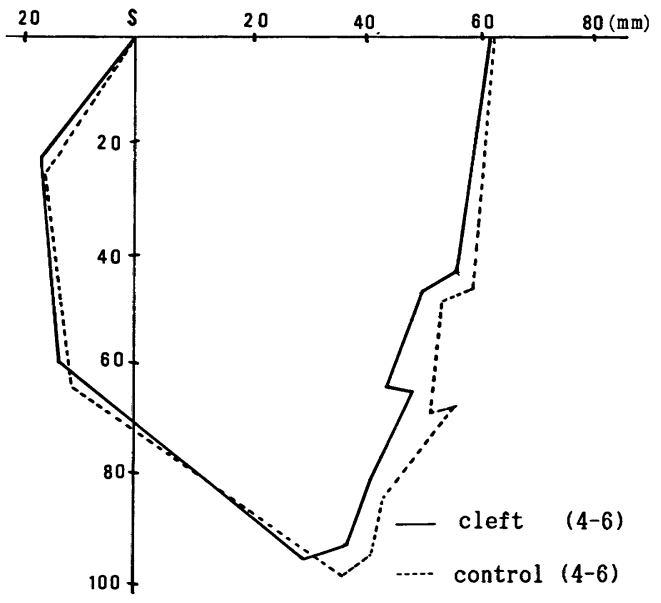

A

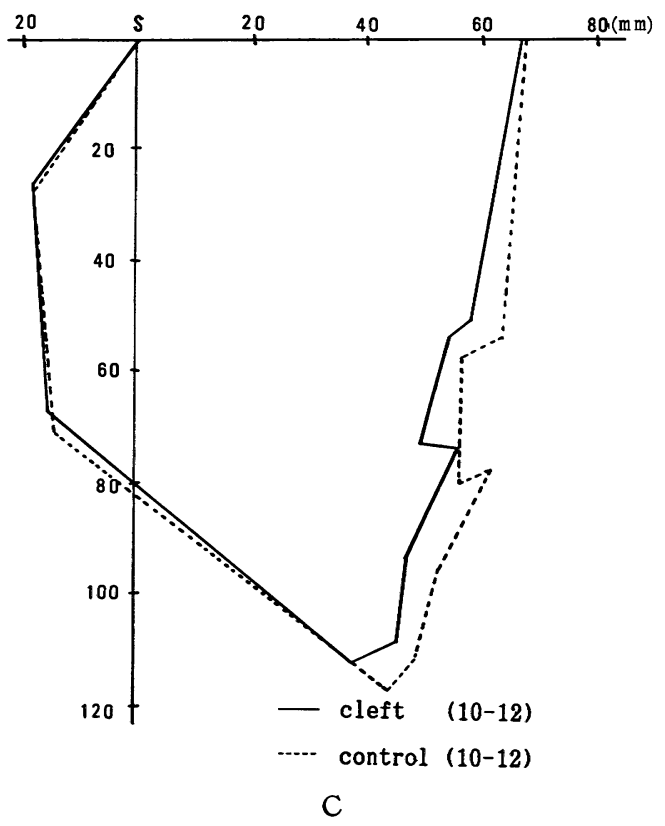

Also, there was no age-related change in Pog in either sample.

The height of the symphysis was significantly greater in the cleft sample as compared with controls.

Similar increase in values occurred concomitant to the increase in age. Virtually no changes were observed in all groups of

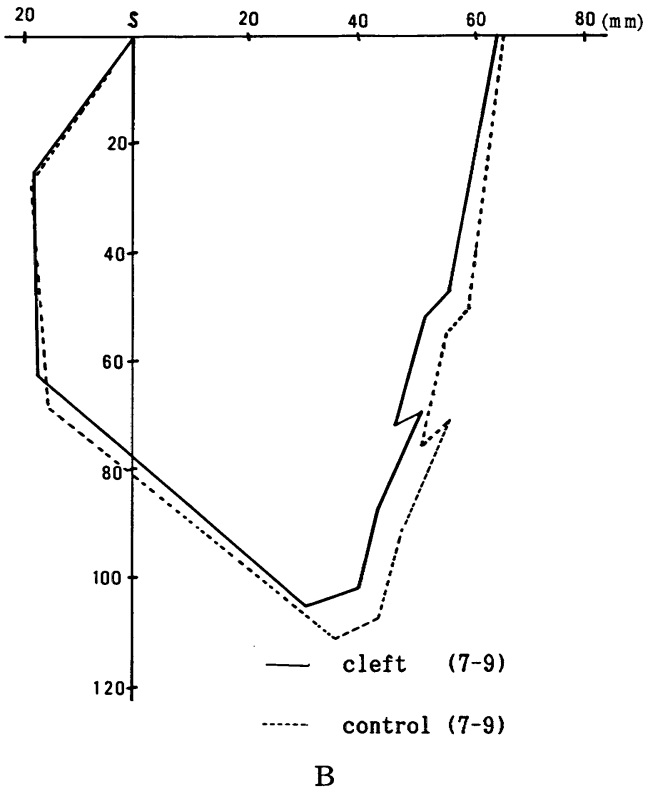

Fig. 6. Superimposed cephalograms comparing the cleft versus control within each Group A, B and C. A, B and C represent Group $A, B$ and $C$, respectively. the controls.

Lingual inclination of the symphysis was siginificantly smaller in all groups of the cleft sample relative to controls; the symphysis was inclined much more lingually in the cleft sample.

Lingual inclination decrease with age in both the control and cleft samples; sig- 
nificant decrease was noticed between groups A and B in both samples.

\section{Discussion}

\section{Materials}

The subjects' age ranged from 4 to 12 years old with complete unilateral cleft lip and palate crossbite. All underwent previous cleft lip and palate reconstruction surgery, but no subsequent bone graft, pharyngeal flap operation or any other secondary operation and pre- or post-orthodontic therapy.

Non-cleft crossbite subjects were chosen as the controls rather than patients with normal occlusion derived from the general population. This choice of controls was based on the findings of Ishikawa et al. (1970) and Hayashi et al. (1985) that most of cleft lip and palate patients receiving orthodontic treatment exhibit crossbite and developmental deformity of the maxilla; much of the treatment effort is focused on correcting the crossbite.

The two groups were compared and evaluated cephalometrically for morphologic differences in order to ascertain whether the actual orthodontic treatment will bring up differences between these groups.

Furthermore, the population studied was cross-sectional in nature, as all the cleft and palate patients require treatment of their occlusion at the time of their initial visit.

This investigation dealt with the preadolescent subjects at the time prior to their greatest growth spurt period. Thus, sex was not considered in this study since no significant differences were inoted between the males and females with respect to the parameters evaluated.

Most of the cleft lip and palate reconstruction operations were performed at the Oral and Maxillofacial Surgery Department of Kurume University School of Medicine. The specific techniques involved were the
Tennison method for the cleft lip cases and modified Wardill pushback operation for the cleft palate cases. Since all the operations were performed identically, they ought not introduce a variability factor with respect to the data.

Cleft lip operations were performed on the average at 3 months post-birth.

The cleft palate operations were performed on the average at 1 year 6 months of age. On the average the cleft lip and the palate surgery were performed 1.3 and 1.1 times, respectively. Operation frequency and timing did not seem to influence the data significantly.

\section{Cranial Base}

McNeil (1963), Levin (1963), Brader (1957) and Sekiguchi (1971) reported no significant morphologic difference in the antero-posterior diameter of the cranial base in the cleft patients, as compared to the normal control sample. However, for the unilateral and bilateral combined cleft lip and palate patients, Dahl (1970) reported flattening and shortening tendencies of the cranial base as compared to controls. Furthermore, Ross (1965) and Aduss (1971) reported short cranial base for the cleft lip and palate patients, and related this tendency to the small body size.

On the other hand, Susami (1967) reported a small $\mathrm{S}-\mathrm{N}$ value for the mandibular prognathic sample when compared to the normal control sample. In the present investigation, no significant difference in the $S-N$ value was found between the cleft lip and palate samples versus the noncleft crossbite sample. However, the cleft lip and palate samples showed a small tendency when compared to controls described by Susami (1967). It must be added that this finding is related to the recession and lack of growth of the maxilla.

Although Aduss (1971), Ross (1965) and Sekiguchi (1971) found no difference in the NSAr cranial base angle value between cleft and non-cleft subjects, Blaine (1969), 
Dahl (1970), Shibasaki (1973), Hayashi (1975) and Hasegawa et al. (1978) reported that NSAr angle increased in the cleft lip and palate sample. In this study, although no significant difference in the NSAr was found between the cleft palate versus the non-cleft crossbite samples, in general the value for NSAr was relatively large in cleft palate sample resulting in a flattening tendency of the cranial base angle.

Antero-posterior diameter of the cranial base was somewhat smaller in the cleft lip and palate sample in comparison to the controls. In addition, the cranial base angle was flattened in the cleft sample. Blaine (1969) reported the upward displacement of the anterior cranial base area and suggested that it was caused by the exertion due to the vomer bone growth. Furthermore, Subtelny (1955) and Nakago (1964) found that there is a correlation with the lateral expansion of the internal plate of the sphenopterygoid process. Thus, it is thought that our findings appear to relate to the flattening of the cranial base angle.

\section{Maxilla}

In general, the maxilla complex grows in a downward/forward direction due to the sutural development of the frontomaxillary, zygomatic maxillary, zygomaticotemporal and pterygopalatine sutures (Bjork, 1966; Enlow, 1971; Salzmann, 1954; Graber, 1949). In addition, Susami (1967) reported that the mandibular prognathic patient's maxilla also grow in the downward/forward direction similarly.

In contrast, as reported by Blaine (1969) Dahl (1970), Sekiguchi (1971), Shibasaki (1973) and Hasegawa et al. (1978), the maxilla is positioned in an upward/posterior location in relation to the cranial base, and this trend increases concomitantly with age. As a result, the mid-facial area exhibits a pronounced concavity "dished-out look", a pathognomonic profile of the cleft lip and palate patients. In the present inves- tigation, the ANS, A and Ul in cleft samples was situated in an upward/posterior position in comparison to the non-cleft crossbite subjects, as shown in Fig. 5 and 6.

The antero-posterior diameter of the maxilla was measured by calculating the linear distance between points $\mathrm{A}$ and $\mathrm{Ptm}$, as projected perpendicularly to the $\mathrm{FH}$ plane. As pointed out by Sekiguchi (1971), the use of Ptm as the measurement point does not adequately describe the mesiodistal dimension of maxilla since it does not take into consideration the height and width factors. Despite this drawback, within the context of this unique form of the cleft lip and palate structure, Ptm is the best choice in describing the distal end of the maxilla (Shibasaki, 1973).

The cleft group showed a significant growth deficiency of the antero-posterior length of the maxilla in all three Groups A, B and C. Slight growth could be observed in the 7 to 9 years age bracket in the cleft sample; virtually no growth took place beyond this age bracket. In contrast, the control sample showed increase in anteroposterior length concomitant with age. This observation concurs with the results reported by Graber (1949), Levin (1963), Shibasaki (1973) and Hayashi (1975).

Hayashi et al. (1985) compared the cleft versus the crossbite samples with respect to SNA angle in relation to cranial base of the maxillary basal arch, and found no significant difference in point A retropositioning. However, in the present study the SNA value was significantly smaller in the cleft sample versus the control sample, with an obvious retropositioning of point A. There was virtually no change with age in the SNA angle in the control sample, as reported by Susami (1967), Ohnishi (1969) and Hayashi (1975); and the position of point $\mathrm{A}$ was stable relative to the cranial base. In the cleft sample, angle SNA was slightly decreased with age.

The upper anterior facial height $(\mathrm{N}$ - 
ANS) was significantly smaller in the cleft verus the control sample.

As reported by Sekiguchi (1971), Minaba (1972), and Shibasaki (1973), the fronto-facial height displayed a shortening phenomenon. It appears that not only the mid-facial region of the cleft lip and palate patients shows an antero-posterior growth change, but also the vertical growth potential seems to be influenced.

On the basis of these findings the etiology of the lack of growth of the cleft lip and palate patients' maxilla may be speculatively related to:

1) Excessive amount of oral surgery interventions;

2) abnormal force caused by the scar tissues and peripheral tissue hypertonicity;

3) lack of growth of the maxilla which occurred following the collapse of the maxillary basal arch;

4) the alteration of the growth potential of the individual.

Fukuhara et al. (1974), Sakuta et al. (1978), Nakagawa et al. (1983), Kitamura et al. (1976), and Ortiz-Monasterio et al. (1959) reported normal growth pattern of the maxilla in the cleft palate cases who did not receive surgical interventions. Taking this into consideration, it may be hypothesized that in essence the growth potential of the subjects with the craniofacial complex of the cleft lip and palate is within the normal limits.

The U-I to SN angle formed between the upper central incisor axis and the cranial base, was significantly smaller in the cleft sample, with the upper centrals showing marked lingual inclination. In addition, similarly slight lingual inclination of the upper centrals in this crossbite group was found when compared to Susami's normal control sample (Susami, 1967).

It appears then that the occurrence of the severe upper centrals' lingual inclination is a clinical characteristic of the cleft lip and palate patients. Similar finding have been reported by Dahl (1970),
Yamauchi et al. (1972), Ohnishi (1969), Hayashi (1975) and Hayashi et al. (1985).

With increase in age, upper incisors of the cleft samples showed slight lingual inclination, although those indicated labial inclination in the control samples. It was suggested that the linguoversion of the upper central was caused by the keloid (scar contracture) due to surgical manipulation at the lip, as well as by the infiltration of periodontal fibers into the scar tissue at the palate after palatal reconstruction surgery (Ross, 1970; Shibasaki, 1973).

\section{Mandible}

As described by Enlow (1971), the mandible develops in general in an upward and backward direction due to the bone remodeling where apposition takes place along the posterior border of the ramus and resorption occurs in the anterior border of the ramus. Furthermore, bone apposition takes place at the alveolar process and cartilagenous appositional remodeling occurs at the condyle resulting in the growth vector stated above.

Susami (1967) reported that in the mandibular prognathic subjects, the chin area and point $\mathrm{B}$ move anteriorly and become prognathic concurrent with age. Altogether, there is an excessive growth of the mandible as compared to the normal control group.

In contrast, the mandible of the cleft lip and palate patients occupies a posterior position relative to the cranial base as compared to the normal controls. When the flattening of the cranial base angle occurs concomitant with the growth, facial prognathism decreases causing growth suppression of the posterior facial height, resulting in a posterior rotation of the mandible (Bjork, 1966). Furthermore, Dahl (1970), Levin (1963), Ford (1958), Shibasaki (1973) and Hayashi (1975) reported shortening of the length of the mandible body, while Hama (1974), Dahl (1970), Sekiguchi 
(1971) and Shibasaki (1973) described shortening of the ramus height. Furthermore, Hama (1964), Aduss (1971) and Shibasaki (1973) reported increase in the gonial angle, and Shibasaki (1973), Deuschle and Kalter (1962) and Pruzansky (1955) increase in the mandibular plane angle.

In the present investigation, the ramus height Ar-Go and mandibular body length Go-Me were also significantly smaller in the cleft population as compared to the non-cleft crossbite subjects (control sample).

The difference increased with age in both samples.

Thus, the mandible of the cleft exhibits hypogrowth in the anthropometric measurements. This may be attributed to such influences as an intrauterine factor hindering the mandibule growth potential, nutritional disorders and oral surgery interventions.

The SNB angle of the cleft groups A-C was significantly smaller at all ages. This indicates that the point $B$ of the cleft sample is positioned posteriorly. In contrast, in a typical skeletal Class III case, the mandible shows hypergrowth with point B positioned anteriorly and concomitant crossbite. It may be suggested that the jaw morphology of the cleft differs substantially even between similar crossbite subjects.

The mandibular plane angle, SN-MP, in subjects characterized by normal occlusion is stable up to the dental age IVA period: beyond this stage, the mandibular plane angle decreases (Iizuka, 1958). Landa (1952) also reported that up till 12 years of age virtually no change takes place in the angle: there is however a slight decrease subsequently up to 18 years of age.

Although it is generally agreed that large mandibular plane angle is indicative of mandibular prognathic patient (Sanborn, 1955; Hellman, 1931; Crain, 1955), Susami (1967) reported that mandibular prognathic patients exhibit smaller mandibular plane angle.

As mentioned earlier, there were many reports concerning the increase in the mandibular plane angle patients with cleft lip and palate, which concurs with this investigation's findings. As for the gonial angle, it was larger in the cleft group in comparison to the non-cleft crossbite subjects, however, no change was seen with age. This positional anomaly of the mandible is caused to the additive effects of such factors as unusually short ramus, large mandibular plane angle, and large gonial angle. According to Ross (1965), the malposition of the mandible is caused by caudal displacement of the tongue as a result of constricted maxilla and inferior displacement of the palatal vault. On the other hand, Hama (1964) states that this phenomenon is the net functional response to the hypogrowth of the maxilla. Shibasaki (1973) states that as a response to the volumetric decrease of the oral cavity and the pharyngeal space, there is a physiologic and morphological adaptation to the abnormal condition.

The ramus angle did not differ between samples according to Susami (1967) and Hayashi (1975). In the present investigation, the angle was small in all groups of the cleft sample, and the clockwise rotation of the posterior border of the ramus was observed. Thus, the steep mandibular with the retrusion of point $B$ and postero-inferior rotation is still another clinical characteritic of the cleft sample.

L-I to MP angle was significantly smaller in the cleft sample, whereby the lingual tipping of the lower anteriors was observed. Similar findings were noticed in the mandibular prognathic subjects. As suggested by Graber (1949), Hama (1964), Shibasaki (1973), and Hayashi (1975), in the case of non-cleft crossbite subjects, this phenomenon may be caused by the hypertonic lower lip and palate patients display stronger linguoversion tendency. This lin- 
gual inclination of mandibular incisors may be attributed to such factors as upper lip dysfunction due to the keloid (scar contracture), and the hypertonicity of the lower lip caused by the retrusion of the maxilla and linguoversion of the upper anteriors.

\section{Maxillo-Mandibular Relationship}

In this investigation, the intermaxillary alveolar base difference, ANB angle, was significantly smaller in the cleft sample for all age groups in comparison to the controls (non-cleft crossbite subjects).

Both samples showed decrease of the angle with age. The control sample in this study showed a similar tendency to the Susami's crossbite sample (1967). These findings were virtually identical with those reported by Shibasaki (1973), Hayashi (1975), Hasegawa et al. (1978) and Hayashi et al. (1985). Although Susami (1967) reported a significant finding during Hellman's IIIA to IVA period in crossbite subjects, this was probably due to the excessive growth of the lower jaw rather than to the lack of growth of the maxilla. Contrary to the cleft subjects, it is thought that the lack of growth of the maxilla constitutes the true etiology of the maxillomandibular mal-relationship rather than the excessive growth of the mandible; this phenomenon is getting worse with age. One must protract the maxilla using the orthopedic force at the early age in cleft samples.

\section{Mandibular Symphysis}

The size, shape and morphology of the chin region has very much to do with the treatment plan, whether this treatment ought to be extraction or non-extraction, and surgical or non-surgical interventions. Also, it is of vital importance to consider the growth potential and other alterations that occur at the mentalis region during orthodontic treatment. However, to date only a few investigations regarding this subject are available. The following list includes some of the notable studies: 1) the study of normal occlusion versus Class III mal-occlusion subjects by Jacobson et al. (1974); 2) the study of skeletal Class I crossbite versus skeletal Class III crossbite subjects by Susami (1967); 3) the investigation of adult skeletal mandibular prognathism versus normal occlusion subjects by matsuda (1982); and 4) the evaluation by Kameda et al. (1982, 1985) of mandibular prognathic subjects symphysial alterations in following orthodontic therapy.

As stated earlier, morphology of the mandibular symphysis limits the types of orthodontic treatment which are feasible. Thus, this investigation compared the morphologic difference and changes concomitant with age between non-cleft crossbite subjects versus cleft lip and palate crossbite subjects.

The thickess at point $\mathrm{B}$, in comparison to the controls, was significantly smaller in the cleft samples as compared with cross-bite controls. Although the point B thickness decreased with age in both the cleft and the control subjects, this decrease was significant in the case of groups B and $\mathrm{C}$ of the cleft sample. Thus, the anteroposterior width of the alveolar ridge was extremely narrow in the cleft samples in comparison with the controls. Furthermore, this thickness decreased with age, in agreenent with the result reported by Atkinson (1942). This decrease was pronounced in the 7 to 12 years old of the cleft sample. This is believed to be related to the amount of overjet increase due to the lack of growth of the maxilla and the severe lingual inclination of the lower anterior teeth at that age.

Although the width at the Pogonion was somewhat smaller in the cleft sample in comparison to contrals, the difference was not significant. Similarly, this parameter decreased somewhat with age in both samples, but the difference was not significant. It appears that such factors as 
growth changes and overjet had virtually no effect on the pogonion width.

Symphysis height was larger in the cleft sample in comparison with controls. The height increased with age in both samples. According to Jacobson et al. (1974) and Susami (1967), the symphysial height did not significantly differ between the normal occlusion subjects versus the mal-occlusion subjetcs.

However, in the present investigation, the height was greater in the cleft sample. This mandibular alteration may be understood as the secondary effect of growth suppession in the vertical direction of the maxilla. It may be hypothesized that the symphysial lingual inclination also affects its height in compensation for vertical growth of maxilla.

In this investigation the lingual inclination of the symphysis (Sym-MP) was significantly smaller in the cleft sample compared to non cleft crossbite subjects, and the symphysis itself showed lingual inclination. In conjunction to the lingual inclination of the lower anterior teeth, the perioral soft tissues such as the orbicularis oris muscle in relation to the amount of overjet exert strong influence in the region.

\section{Clinical Considerations}

The materials used in this investigation consisted of cleft lip and palate and control subjects with crossbites.

Significant difference was found on the basis of the cephalometric analysis in their maxillomandibular relationship. In other words, although lack of growth of the maxilla was also observed in control samples, the cleft palate subjects showed distinct antero-posterior and vertical growth deficiencies. The non-cleft crossbite sample exhibited excessive growth of the mandible, while the cleft palate sample were characterized by a downward/backward rotation of the mandible with no concomitant excessive mandibular growth. With regard to the morphology of the mandibular symphysis, the alveolar ridge area width was small and the symphysis showed lingual inclination in the cleft sample in comparison with the crossbite samples. These findings indicate that the maxilla ceases to grow, especially beyond the age of almost ten, in the cleft lip and palate patients. It is necessary to guide the growth of the maxilla to the downward/forward direction with the utilization of orthopedic force as early as possible. Furthermore, it appears clearly on the base of the morphology of the symphysis that the orthodontic treatment of the cleft sample is most difficult compared this treatment in the non-cleft crossbite subjects. Altogether, and keeping in mind the limitations of early intervention, orthodontic therapy of the cleft lip and palate patients requires a team approach involving the oral and maxillofacial surgeon, prosthodontist, and plastic reconstruction surgeon.

\section{References}

Aduss, H. (1971). Craniofacial growth in complete unilateral cleft lip and palate. Angle Orthodont. 41, 202-213.

Atkinson, S. R. (1942). Some anatomic factors guiding treatment therapy. Am. J. Orthod. 28, 704-720.

BJoRk, A. (1966). Sutural growth of the upper face studied by the implant method. Acta Odont. Scand. 24, 109-127.

Blaine, H.L. (1969). Differential analysis of cleft palate anomalies. J. Dent. Res. 48, 10421048.

Borden, G. H. (1957). Mandibular growth in the cleft palate infant. Angle Orthodont. 27, 197199.

Brader, A.C. (1957). A cephalometric X-ray appraisal of morphological variations in cranial base and associated pharyngeal structures: implications in cleft palate therapy. Angle Orthodont. 27, 179-195.

Crain, S.D. (1955). The comprehension of diagnostic differentiation of class III cases for the investigation of therapeutics. Am. J. Or- 
thod. 41, 604-619.

DAHL, E. (1970). Craniofacial morphology in congenital clefts of the lip and palate: An X-ray cephalometric study of young adult males. Acta Odont. Scand. 28, 83-166.

Deuschle, F. M. and Kalter, H. (1962). Observations on the mandible in association with defects of the lip and palate. J. Dent. Res. 41, 1085-1095.

Downs, W. B. (1948). Variations in facial relationships: Their significance in treatment and prognosis. Am. J. Orthod. 34, 812-840.

EnLow, D. H. (1971). The growth and development of the craniofacial complex. In Cleft Lip and Palate, ed. Grabb, W.C., Rosenstein, S. W. and Bzoch, K. R., pp. 81-96, Boston: Littl Brown.

FoRD, E. H.R. (1958). Growth of the human cranial base. Am. J. Orthod. 44, 498-506.

Fukuhara, T., Hanada, K., Suzuki, H., Ryokawa, H., Sasakura, H., Kasano, H. and Wakui, Y. (1974). Cephalometric and dental arch analyses on an adult patient of nonoperated cleft palate and review of the references. J. Jpn. Odont. Soc. 33, 56-62.

Graber, T.M. (1949). A cephalometric analysis of the developmental pattern and facial morphology in cleft palate. Angle Odont. 19, 91100.

Graber, T.M. (1949). Craniofacial morphology in cleft palate and cleft lip deformities. Surg. Gynecol. Obstet. 88, 359-369.

Hama, K. (1964). Morphological study of the cranio-facial skeleton within a profile in cleft lip and palate. J.Osaka Univ. Dent. School, 4, 41-67.

Harvold, E. (1954). Cleft lip and palate: morphological studies of facial skeleton. Am. J. Orthod. 40, 493-506.

Hasegawa, M., Nukatsuka, S. and Shibasaki, Y. (1978). A roentgeno-cephalometric study on the dentocraniofacial morphology of the individuals with the complete unilateral cleft lip and palate - Three dimensional analysis of growth pattern -. J. Jpn. Odont. Soc. 37, 37-55.

HAYASHI, I. (1975). Craniofacial growth in unilateral cleft lip and palate: A roentgeno-cephalometric study. J. Jpn. Odont. Soc. 34, 33-65.

HAYASHI, K., KamEda, A. and Hisa, S. (1985). P-A cephalometric study on the dentocraniofacial morphology of the unilateral cleft lip and palate patients with reversed occlusions. J. Jpn. Odont. Soc. 44, 31-49.

Hellman, M. (1931). Morphology of the face, jaws and dentition in class III malocclusion of the teeth. J.A.D. A. 18, 2150-2173.

IIzUKA, T. and IsHikAwA, F. (1957a). Normal standards for various cephalometric analysis in Japanese adults. J. Jpn. Odont. Soc. 16, 412.

Iizuka, T. and Ishikawa, F. (1957b). Points and landmarks in head plates. J. Jpn. Odont. Soc. 16, 66-75.

IızuKa, T. (1958). Cephalometric study of craniofacial growth in Japanese children. Kokubyo Z. 25, 260-272. (in Japanese)

IshikaWa, F., Endo, T., KaMEGai, T. and Kunitake, K. (1970a). An orthodontic study of the cleft lip and palate - On the dento-facial pattern-. J. Jpn. Odont. Soc. 29, 54-60.

Ishikawa, F., Endo, T., Kamegai, T. and Kunitake, K. (1970b). An orthodontic study of the cleft lip and palate - On the dento-facial pattern incident to the type of cleft and the time of the operation -. J. Jpn. Odont. Soc. 29, 149-158.

Jacobson, A., Evans, W.G., Preston, C. B. and SANDowsky, P.L. (1974). Mandibular prognathism. Am. J. Orthod. 66, 140-171.

Kameda, A., Hisa, S., Miyai, T., Oka, K., Hirose, M. and HAYASHI, K. (1982). Morphological changes of mandibular symphysis during orthodontic treatment of Class III malocculusion. J. Jpn. Odont. Soc. 41, 510-520.

Kameda, A., Hisa, S., OKa, K., Kobayashi, S., Endo, R., Moro, Y., TAKada, M. and Chiba, A. (1985). Morphological changes of mandibular symphysis during orthodontic treatment using mainly lower horizontal elastics. J. Jpn. Odont. Soc. 44, 459-470.

LANDA, M. J. (1952). Growth behavior of the human bony facial profile as revealed by serial cephalometric roentgenology. Angle Orthodont. 22, 78-90.

Levin, H.S. (1963). A cephalometric analysis of cleft palate deficiencies in the middle third of the face. Angle Orthodont. 33, 186-194.

Matsuda, Y. (1982). Surgical-orthodontics in the skeletal Class III malocclusions - The morphology of mandibular symphysis and the positioning of lower incisors - J. Jpn. Odont. Soc. 41, 109-116.

Mazaheri, M., Nanda, S. and Sassouni, V. (1967). Comparison of midfacial development of chil- 
dren with clefts with their siblings. Cleft Palate J. 4, 334-341.

McNeIL, R. W. (1963). A roentgen cephalometric study of naso-pharyngeal and cranial base growth in cleft palate children. Int. Assoc. Dent. Res. 41, 53.

Minaba, T. (1972). Studies on growth and development of facial skeleton and abnormality of cervical vertebra in cleft lip and palate patients. Shikwa Gakuho 72, 1269-1318. (in Japanese)

Nakagawa, M., Itoh, T., Kawagoe, H., Fujita, N., Hata, S., Kiyama, K., Matsumoto, M. and Itoh, T. (1983). Cephalometric and dental casts analyses on an adult patient with non-operated cleft palate. J. Jpn. Cleft Palate Assoc. 8, 99-104.

NAKAGo, T. (1964). Morphologic studies of the craniofacial skeleton of cleft palate patient by a postero-anterior roentgenographic cephalometry. J. Jpn. Odont. Soc. 23, 75-88.

Nakamura, S., Savara, B.S. and Thomas, D. R. (1972). Facial growth of children with cleft lip and/or palate. Cleft Palate J. 9, 119-131.

OнNishi, K. (1969). Relationships between apical base relation and incisal inclination in school children: A longitudinal study by lateral cephalometric roentgenograms. J. Jpn. Odont. Soc. 28, 12-32.

Ortiz-Monasterio, F., Rebeil, A.S., Valderrama, M. and CRUZ, R. (1959). Cephalometric measurements on adult patients with nonoperated cleft palates. Plast. Reconstr. Surg. 24, 5361.

Pruzansky, S. (1955). Factors determining arch form in clefts of the lip and palate. Am. J. Odont. 41, 827-851.

Ross, R. B. (1965). Cranial base in children with lip and palate clefts. Cleft Palate J. 2, 157166.
Ross, R. B. (1970). The clinical implications of facial growth in cleft lip and palate. Cleft Palate J. 7, 37-47.

Sakamoto, T. (1959). A study of the developmental changes of dentofacial complex of Japanese with special reference to sella turcica. J. Jpn. Odont. Soc. 18, 1-17.

SaKudA, M. (1978). Cleft lip and palate - With reference to craniofacial growth-. J. Jpn. Odont. Soc. 37, 139-160.

Salzmann, J. A. (1954). General growth acceleration and retardation in relation to dentofacial development. Am. J. Orthod. 40, 243258.

SAnborn, R.T. (1955). Difference between the facial skeleton pattern of class III malocclusion and normal occlusion. Angle Orthodont. 25, 208-222.

Seriguchi, T. (1971). Dentofacial and morphology of repaired unilateral cleft and palate patients - A standardized cephalometric roentgenographical study - . Kokubyo Z. 38, 375-390.

ShIBASAKI, Y. (1973). A roentgenocephalometric study of dento-craniofacial morphology of repaired complete unilateral cleft lip and palate individuals after adolescent growth spurt. Kokubyo Z. 40, 476-497.

Subtelny, J.D. (1955). Width of the nasopharynx and related anatomic structures in normal and unoperated cleft palate children. Am. J. Orthod. 41, 889-909.

SusAmi, R. (1967). A cephalometric study of dentofacial growth in mandibular prognathism. J. Jpn. Orthod. Soc. 26, 1-34.

Yamauchi, K., MiYake, Y., Asakura, S. and HANAOKA, H. (1972). Changes of relative position between upper facial skeletal complex, mandible and teeth from six to eleven year of age. J. Hiroshima Univ. Dent. Soc. 4, 3244. 